\title{
Tell Me Your Story: Narrative Inquiry in LIS Research
}

\section{Emily Ford}

\begin{abstract}
Narrative inquiry, a phenomenological qualitative research methodology, examines individual human experiences - stories. Yet, researchers in Library and Information Science (LIS) - a human-focused profession-have infrequently used it. This article introduces narrative inquiry and provides a literature review of the few LIS studies using it. Next, it extrapolates on Coralie McCormack's "storying stories,"1 a multifaceted approach used to analyze narrative inquiry research data. Finally, the article outlines potential uses for narrative inquiry in LIS research.
\end{abstract}

\section{Introduction}

Each person in our human profession, librarianship, has a story to tell. Stories humanize our experiences for others, and humans have an innate need to narrate. For the past year and a half, I have been asking colleagues to tell me their stories. Not just any stories, but stories about peer review, their relationship to LIS publishing, their experiences of peer review as authors, referees, editors, and readers. This article is not a traditional research article. It does not report on my findings or analyze the stories I have heard and constructed, nor does it pose and answer a research question. Instead, this article offers an overview narrative inquiry, a qualitative research methodology, and shows how it has been used in LIS research, including examples from my own story-gathering. Then, I expand on Coralie McCormack's interdisciplinary narrative inquiry approach - "storying stories" 2 - and outline proposed uses of phenomenological narrative inquiry research in LIS. My goal is to share what I have learned about narrative inquiry and to encourage others to explore its utility for their research.

\section{Quantitative or Qualitative? Research History in LIS}

There are many pressure points in academic librarianship when it comes to research, writing, and the dissemination of new knowledge: the demands of our positions as librarians, the need to achieve promotion and rank, our training (or lack thereof) to engage in research, and the culture of our discipline. There exists a discourse in our community that stresses our need to further our research and research development skills. This conversation also includes dialogue around research method: what kinds to use and how can we expand them?

\footnotetext{
${ }^{*}$ Emily Ford is Associate Professor, Urban \& Public Affairs Librarian, and Scholarly Communication Coordinator in the Portland State University Library; email: forder@pdx.edu. (02020 Emily Ford, Attribution-NonCommercial (http://creativecommons.org/licenses/by-nc/4.0/) CC BY-NC.
} 
These questions undergirded Scott Walter's tenure as editor of College and Research Libraries $(C \mathcal{E} R L)$ and continues today. Conversations in our association and among the $C \mathcal{E} R L$ editorial board have included questions of how the publication can support research skills development. ${ }^{3}$ A turning point of this conversation occurred in 2016, when Emily Drabinski and Walter pleaded with the $C \mathcal{E} R L$ readership to complement research on the value of libraries with research based in library values. Offering a brief history of our community debates about research, what type is valid, what methods to use, they concluded, "Methods give librarians the tools with which to answer research questions central both to curiosity and to daily practice, and having an ample toolbox with which to do that work is important. But it is just as important to know what we want to build and who it will benefit as it is to make sure that we have the tools to do the work." ${ }^{4}$

We have recently seen the utilization of newer and more qualitative methods in LIS research. Drabinski and Walter argue that, although qualitative methods are slowly being more accepted into our profession, they still face challenges. In his book chapter "Evaluative Criteria for Autoethnographic Research," Robert Schroeder provides a good example of these challenges as he presents the responses he received from journal editors when he inquired whether journals would be interested in publishing research using autoethnographic research methods. ${ }^{5}$ Because journal editors did not understand how to evaluate autoethnographic research, he and his coauthors could not find a journal publication willing to give credence to their study. (Luckily, with a little tenacity and hard work, they were able to turn the project into a book published by ACRL Press.)

This is not to say that qualitative research does not get published in LIS journal literature; our literature does include qualitative studies. For example, Benedetti et al. ${ }^{6}$ successfully published their work discussing the use of vignettes as a way for researchers to achieve focused conversations with research participants in interviews and focus groups. Large projects such as the mixed methods grant-funded Ethnographic Research in Illinois Academic Libraries (ERIAL) project produced an ethnography of student research processes. ${ }^{7}$ Although we are increasingly using qualitative methods in LIS research, qualitative-based work remains in the minority. Ahsan Ullah and Kanwal Ameen explicitly show this in their (ironically) quantitative systematic review. They report that 49 percent of articles used quantitative methods, 33 percent used qualitative, and 12 percent used mixed methods. ${ }^{8}$ Further, of the dominant methods used, survey research outpaced all others, with 33 percent. Notable in their findings as well is the long list of rarely used research methods - most of which are qualitative-including phenomenology, participatory action research, contextual inquiry, and others. ${ }^{9}$ Hamid Jamali also sought to understand the impact of qualitative studies in LIS, finding that only 15.4 percent of qualitative articles were phenomenological studies, compared to 42 percent for research articles based in both ethnographic (42.5\%) and grounded theory $(42.1 \%) .{ }^{10}$

So why is the majority of LIS research based in quantitative knowledge? Citing Michael H. Harris, Drabinski and Walter explain that quantitative research has undergirded our profession since its inception. ${ }^{11}$ Moreover, I contend that empirical and quantitative research is more straightforward than qualitative; therefore, it is easier to accomplish. On the whole, it takes less time. For academic librarians whose main duties are to serve patrons, whose education and training is as an applied profession, not a doctoral degree in a research field, it makes sense that straightforward research methods dominate our literature. However, I find that these methods can often be in direct conflict with the human nature of our profession. 
Academic librarians are beholden to the demands of our positions as well as to the demands of our institutions. As Anne-Marie Dietering theorizes in her introduction to The Self as Subject, librarians lack a focus or theory, which may precipitate institutional needs coming to dictate librarians' research agendas and approaches. ${ }^{12}$ "If my untested theory is true, this also shapes how we think about research. If institutional requirements are the primary factor we use to make research choices, then that starts to shape what we think research is for."13 We may also work in environments where we must assert ourselves culturally among our disciplinary faculty peers. Yes, many academic librarians are faculty who must also engage in research and writing. Since quantitative approaches to research are still more widely accepted in the academy, this may also lead to the predominance of LIS research using quantitative research approaches. Whatever the reasons, qualitative research has not been fully explored in our discipline.

\section{Narrative Inquiry}

Narrative inquiry is a type of qualitative research focused on human stories. It examines human experience through life story interviews, oral histories, photo voice projects, biography, autoethnography, or other human experience narrative methods. The purpose of narrative inquiry, according to educational researcher Jeong-Hee Kim, is to “. ... invite readers to a sphere of possible contact with a developing, incomplete and evolving situation, allowing them to re-think and re-evaluate their own views, prejudices, and experiences." ${ }^{14}$ As you might imagine, there are many approaches to the examination of human experience under the umbrella of narrative inquiry. For Donald E. Polkinghorne, these approaches can be lumped into one of two types-paradigmatic or narrative analytic type. Paradigmatic analysis "...seeks to locate common themes or conceptual manifestations among the stories collected as data."15 In contrast, narrative analytic type "...requires the researcher to develop or discover a plot that displays the linkage among the data elements as parts of an unfolding temporal development culminating in the denouement."16 According to Polkinghorne, paradigmatic types are an "analysis of narrative," and narrative analytic types are "narrative analysis." "Thus, analysis of narratives moves from stories to common elements, and narrative analysis moves from elements to stories."17

Most narrative inquiry research performed in LIS adheres to the paradigmatic type, frequently using grounded theory as an approach to create codes and categories for data. Grounded theory approaches an understanding and interpretation of data categorizing data from the ground up (rather than creating categories before examining data) and coding narrative text for analysis. This approach can rely too heavily on machine thinking to categorize individual experiences. Other paradigmatic types of narrative inquiry might use comparative analysis of research participants' interview transcripts.

In this article I offer a view into the narrative analytic type of narrative inquiry research that brings this idea to bear. I highlight "storying stories," a multidisciplinary approach developed by Australian researcher Coralie McCormack. ${ }^{18}$ It is a human-focused method in a human-focused methodology and can provide humanistic results. It is rooted in the value of understanding individual lived experiences and uses them as a mirror to reflect and re-evaluate our own views and practices. But before I go on to discuss "storying stories," I offer for you a brief view into the few studies in LIS reporting use of narrative inquiry methods. 


\section{Narrative Inquiry in LIS}

In-depth narrative inquiry research in LIS is not fully established. It is a time-consuming undertaking, a luxury not afforded to academic librarians seeking promotion and tenure, especially given the heavy instruction and patron-centered workload of most academic librarians. As I previously mentioned, researchers engaging in narrative inquiry may encounter barriers when it comes to sharing and publishing their works. Despite these challenges, librarians are beginning to recognize its value. Donna Lanclos, in her 2016 Insights article, writes "...we cannot get to these sorts of things [the experience of being a person] with analytics and systems. We have to get to this kind of information by engaging in practices that bring us in contact with people. We have to talk to them, we have to observe them, we have to ask questions, we have to not just take their word for it when they say they do something, but we have to dig deeper and find out what they actually mean..."19

There are a handful of studies that have taken narrative inquiry approaches. It is notable that most of the narrative inquiry studies completed in LIS are products of LIS Faculty researchers, doctoral students, or studies conducted with external funding. On-the-ground working academic librarians have not engaged in most of these studies, with the exception of authors published in The Self as Subject. (I should note that my ability to do this work is supported by having already achieved tenure, and much of the work has been conducted during a full-year sabbatical. I am well aware that this is a great privilege that has allowed me to conduct this research, and that it presents an example of institutional barriers librarians face to participate in research.) Published narrative inquiry studies in LIS journal literature stem from both paradigmatic and narrative analytic approaches and can be lumped into one of three categories: studies on the evaluation of system development and implementation; studies of school librarian careers; and studies pertaining to students and information literacy.

\section{Systems Development and Implementation}

A few studies using narrative inquiry in LIS deal with the evaluation of systems development and implementation. These studies are part of mixed-methods research, presenting paradigmatic approaches to narrative inquiry. For instance, Bonnie Cheuk used a "sense-making paradigm" to analyze narratives, detailing how collected narratives were then cataloged into a database to assist managers with FAQs regarding a knowledge management system. ${ }^{20}$ Cheuk approached this design as a way to "...to capture and transfer lessons learnt in a meaningful way so as to maximise the number of individuals and departments who can benefit from them over an extended period of time..." ${ }^{21}$ Similarly, Rich Gazan used narrative inquiry as part of the evaluation phase of a large, multi-institutional grant-funded digital library project. ${ }^{22}$ This project team saw narratives as a way to improve systems design, using the paradigmatic narrative analysis approach to make sense of participant stories shared during that project. Both of these approaches used narrative inquiry to improve a system, not to understand contextualized, individual human experiences as the research end point. In this sense, the paradigmatic approach to narrative inquiry research is appropriate for the research's end goal.

\section{School Librarian Careers}

Some studies in LIS have used narrative analytic type approaches to narrative inquiry in their attempts to understand individual and contextualized experiences. Both Jones ${ }^{23}$ and Mardis $^{24}$ separately investigated school librarians' careers. Jones offered personalized contextual sto- 
ries of school librarian career choices, which they then interpreted using career construction theory, offering an example of one way to analyze narrative inquiry findings. Moreover, Jones offered readers a unique view into narrative inquiry methods, rarely accomplished in the literature. ${ }^{25}$ Like Jones, Mardis articulated a narrowly scoped research question and applied an appropriate theoretical framework, critical event narrative analysis, to examine data. Both authors present scoped narrative analytic research questions and appropriately matched their articulated research questions with theoretic analysis frameworks.

\section{Students and Information Literacy}

The final theme examined with narrative inquiry methods in LIS literature relates to the information literacy classroom. The ways in which researchers express these studies varies. For example, Frances Hultgren offers a case study. Hultgren culled the story from a much larger grant-funded study on the experiences of youth in Sweden and their practices of information seeking after leaving school. The case study offers a view into one immigrant student's lived experience, framing that experience with the concept of "the stranger" and allowing Hultgren to "...to depict the entire experience of preparation for leaving school in terms of information seeking, but more to examine the usefulness of the stranger metaphor by applying it to stories of information seeking as articulated by a young person who also happened to have an immigrant background. I argue that the stranger metaphor facilitates a better understanding of the social and cultural world in which information seeking occurs." ${ }^{26}$ Alcalá and their coauthors used narrative inquiry as part of a classroom activity. ${ }^{27}$ Students in an LIS course with diversity and cultural inclusivity components completed a digital storytelling assignment. Based on those stories, the researchers constructed themes, using those themes as a basis for a call-and-response dialogue with student participants. What resulted was the ability for students to share their lived experiences as persons of color and for their classmates to listen and rethink and re-evaluate their own views and experiences. Finally, Kim L. Morrison used narrative inquiry components in their work on asset-based pedagogy. ${ }^{28}$ By layering autoethnography with counter-storytelling, Morrison, in partnership with students, used lived experiences to create an asset-based pedagogy in the information literacy classroom. These three studies each make a case for using lived experience as a mirror for collective reflection and awareness. They communicate individualized and contextual experiences to allow outsiders to think and re-evaluate.

\section{Storying Stories}

While researching methodologies and methods to continue my own investigation of open peer review, I found "storying stories" highlighted in the SAGE Handbook of Narrative Inquiry. ${ }^{29}$ After reading about it, I immediately knew it would be my approach for the continuation of my research. My project goal-to gather and share individual human experiences of peer review and openness - were well aligned to the "storying stories" approach.

"Storying stories" was developed by Coralie McCormack, who used this multidisciplinary approach during her dissertation work, studying female graduate students' lived experiences of leisure. ${ }^{30}$ It pulls from feminist research approaches that seek to unpack social and cultural contexts of power and domination, sociolinguistics, and critical resistance theory. In essence, it is a pastiche of complementary approaches pulling from many social sciences disciplines. McCormack's "storying stories" method requires a researcher to reflect on their own relational, 
emotional, and intellectual responses to an interview. These reflections become a part of an interpretive story, the culminating document of a researcher's work with each individual research participant. In short, the interpretive story is part interview transcript, part analysis, and part reflection.

The interpretive story is a synthesis of an analyzed interview transcript and can include a researcher's emotional and intellectual reflections, as well as any of the interviewee's responses to the researcher's analysis and reflections. In interpretive stories, the researcher acknowledges her presence as well as the social context of an interview process. In this way, the development of an interpretive story is a collaboration between interviewer and interviewee and distinguishes the process from traditional interview and transcript analysis techniques. Because interpretive stories deeply explore social contexts and involve close work with interviewees, they are better able to provide detailed individual pictures of experience than does traditional interview analysis.

This collaboration mirrors action research in education and social work. Action research seeks not to colonize their research subjects, instead forming research in collaboration with participants. To Debbie Pushor and D. Jean Clandinin, narrative inquiry work is interconnected with action research in that their approach to narrative inquiry includes growth and change. ${ }^{31}$ This growth and change can occur for interviewees as they formulate, retell, and evaluate their own stories, as well as for interviewers as they learn with interviewees. By allowing interview participants to reflect on a researcher's analysis, McCormack's process allows for this growth and change in each of these roles. As Gail Crimmins discusses in their book chapter, "The Intrinsic Pleasure of Being Present with/in Humanistic Research," inquirers are both intellectually and emotionally present in humanistic research, whether or not that presence is reflected in resulting written works. ${ }^{32}$

What is offered in an interpretive story, too, is a reconstructed story. During the analysis process, the researcher reorders transcript text into a cohesive and readable narrative that speaks to the research question. Borrowing from William Labov, McCormack defines stories as those that have a beginning, middle, and an end, as well as an evaluation of the narrated events. ${ }^{33}$ By reconstructing stories, researchers are able to craft a readable and understanding narrative that more coherently addresses her research questions.

But interviewees don't just tell stories. They use mechanisms of language as well as constructions and performances of social contexts and roles throughout an interview. Storying stories honors all of these, asking researchers to provide their own intellectual, relational, and emotional responses to an interview, reflecting on potential power dynamics in the social context of interviewing (feminist approaches), as well as to analyze an interview for language use, textual construction, and the interviewee's narratives of challenge, resistance, and accommodation to cultural norms (resistance theory). When an interviewee is not telling a story, they are theorizing, arguing, describing, or augmenting previously told stories. Storying stories makes space for multiple modalities and lenses through which to view an interview and weave a narrative.

My own research project focuses on LIS experiences with peer review and openness. My aim in this work is not only to understand individual experiences of peer review and openness but to be able to share those experiences with the LIS community. In other words, I adopted narrative inquiry for myself, research participants, and members of our LIS Community so that we may start rethinking and re-evaluating our individual and collective experiences and 
views of peer review and openness. The following excerpt provides an example of a storied story from this research project. The excerpt comes from Julie's interpretive narrative, I like that melding of voices into one. Julie is an experienced academic librarian and author who, both as an author and librarian, values collaboration and community. In the excerpt below, font and formatting denote voice as well as separate analysis, reflection, and parts of the direct transcript.

This theme of valuing community and the fear of loneliness seems to permeate Julie's perspective as well as her emotions in [regard] to her work both in research and writing, but as well as her service. As I asked more about withdrawing articles from publications, this becomes even clearer.

But you've withdrawn articles...

I was wrong. One article....We actually threatened to withdraw our other article. This is an article that is currently under review. And that article has been under review, I want to say since January. And threatened-we threatened to withdraw it and they were like "no, no just a couple more weeks, a couple more weeks." I'm not the lead author on this article. And we finally got reviewer feedback ... . That feedback arrived in June so it was over six months. And so now we have our revisions that are getting ready to go back now. And then, I don't know, I have a feeling there's probably also a pretty large publication delay too, like they have a backlog in that respect also.

I guess my question for you in both of these instances like one, you did withdraw an article, and two, the second one you threatened to and then that made the hamster run on the wheel faster or something.

I mean kind of. They would just kind of buy time. Like again, I wasn't really the main person having the negotiations, but my co-author, who is the lead author on this, she'd be like "we are done with you guys." And they'd be like "we promise we'll get it to you by the 15th, we'll get our feedback to you." 15th would come and go and she would be like "where is the feedback?" And they'd be like "it's coming one more week." So they kept trying to like buy time. "We're really understaffed. PS, nobody understands your topic area... so we don't really have reviewers." Like they just kept offering excuse after excuse after excuse. Finally it got there.

(At this point in our conversation Julie is using a higher-pitched voice to indicate the voice of the editors, more so than she has used pitch to relay other stories throughout our conversation.)

At the time Julie reviewed her story draft (four and a half months after our initial conversation), she updated me on this article. It was still unpublished, but in copyediting. 
In our analysis process I reflected on Julie and her coauthor's experience:

Intellectual Response Would open peer review solve this problem of not having reviewers who understand the topic area? Allow the community to decide? Or recruit reviewers who know parts of it

but not others?

She responded: "That would REALLY solve the problem! It would also bring greater transparency to the range of topics under consideration for publication in journals like this one."

And so you feel like you mentioned, when you first mentioned the withdrawal, no transparency in process at that journal.

Yeah. And not at this journal either, in this journal it's the same thing. My coauthor would keep emailing me and she'd be like "what does this status mean?" It would be again like some super-opaque status. And that is all just really frustrating. It really is. But then I would love, on the other side, too, like once an article is published I would love to have more of a community around that as well-of openness and commenting because some journals even allow that, like right next to the article is a field that people can post comments and questions and there just isn't engagement around that either. So I would love to see it around both sides of the process.

Since Julie was working with a coauthor, she has community in her feelings of frustration, just as she wants community in the entirety of the peer-review process, which she didn't feel like she was getting from the journal. Too, it is clear that because Julie is not publishing this on her own, she must accommodate how she reacts, working in tandem with her coauthor.

\section{Uses in LIS}

I propose that using narrative inquiry in LIS research, and particularly narrative analytic approaches such as "storying stories," can achieve three things. First, it will help us broaden LIS literature. Narrative inquiry offers an additional qualitative approach to research in the sea of quantitative. Further, using narrative inquiry is a powerful response to Drabinski and Walter's request to base library research in library values. Like library values, narrative inquiry is human-focused and would offer contextualized understandings of human experience that we can apply to our human-focused field of librarianship. Next, narrative inquiry holds utility for us to better understand the lived experiences of library patrons in their authentic contexts, so that we may better respond and adapt to patrons' needs. Finally, narrative inquiry research will allow us to better understand individual experiences within our own LIS community and opens up the possibility for us to reflect and reimagine those experiences not yet had. The first of these three arguments is straightforward and needs no further explication. Below, I further discuss the utility of understanding contextualized, individual experiences and how to harness these findings to improve our communities 
for our patrons and services, as well as to improve systems and practices within our own profession.

Narrative analytic approaches to LIS research can uncover contextualized, individual lived experiences of students and patrons, all so that we may improve our services and practices to better serve them. As we serve our patrons, understanding individual lived experiences is an embodiment of our humanistic profession. We focus on the experiences patrons have with our systems, at our service desks, in the classroom, during consultations in our offices. If tied into the information literacy classroom, storying stories can honor social contexts and students' lived experiences. Morrison's article detailing their work to use narrative inquiry methods, including storying stories and autoethnography, concludes, "in this study the use of student voice placed students as experts in an environment that has seen them as being in deficit... In concluding this article, I harken back to what I believe the skills of an asset-based-minded teacher/researcher does; it is to understand what my students bring in their own terms." ${ }^{34} \mathrm{In}$ short, using narrative inquiry allows patrons and students to become the experts, offering libraries and librarians a rich opportunity to make needed changes that better serve them. In this way, narrative inquiry can complement quantitative and qualitative methods already used in LIS research, thereby providing a more robust picture of our library landscapes.

Similarly, narrative inquiry and storying stories can be used as a tool for our own library community to identify issues and to reflect on and rethink them. While conducting what Kim calls "backyard studies" can be problematic, they can be powerful tools for change if approached with "caring reflexivity." 35 "Storying stories" or other forms of narrative inquiry provide avenues through which we can listen to our colleagues' lived experiences.

Andrew Sparkes offers a good example of this reflection and reimagining in his moving article "Embodiment, Academics, and the Audit Culture." ${ }^{36}$ Sparkes offers readers a narrative "...inspired by partial happenings, fragmented memories, echoes of conversations, whispers in corridors, fleeting glimpses of myriad reflections seen through broken glass, and multiple layers of fiction and narrative imaginings. ${ }^{37}$ In this narrative, Sparkes exposes the detritus of academia, the push in universities to produce a large quantity of high-impact research. As part of this article, Sparkes included informal and formal reviewer comments. These comments make clear that, when we hear others' stories, we think about our own and how we can change our own narratives:

Forgive my rant, but the essay did for me what I believe an excellent essay of this kind can do: It made me think about how legislative policies have genuine consequences for individual lives. It allowed me to see more fully the complexity, both conceptually and emotionally, of the problem. It reminded me how the literary can have power within the social sciences (the essay is masterfully crafted). It persuaded me that change is needed. Quite honestly, after finishing the paper, I simply sat in my chair, stunned, depressed and moved. It made me want to reach out. It made me want to take action. So, I thank the author again for sharing his beautiful piece. What a gift! ${ }^{38}$

This same kind of reflection can occur during interviews and the storying stories process. For example, in my own research, several interviewees reflected on their experiences during our conversations. Stephanie, a tenured mid-career academic librarian, reflected on her lack of 
experience with open peer review during the interview. "I have not actually [had experience with it]. That's on my list of things to try." Others thanked me for being open to their questions about open peer review during the interview, coming away from the interviews with a changed perspective. For John, our conversation reassured him. "I'm excited to see from a practical standpoint how it's going to look. So thank you for reassuring me by saying it's not all or nothing. We can take small bites."

Because "storying stories" invites interviewee participation in the development of their interpretive narratives, there remains an invitation for both the interviewee and the researcher to continue their reflections and reimaginings. This is related to Pushor and Clandinin's view that interviewees can grow and change throughout the interview process. ${ }^{39} \mathrm{Julie}$, the participant whose story excerpt I shared, commented on part of her first interpretive story draft, "This project has been like a therapy session for me! You are so right about this - and I never realized it. I feel deep anxiety when I don't have a colleague to confront the challenges of a project alongside me. I never realized that before-I always thought that I functioned better as a solo author." Julie's ability to read my perspective, to see how the threads of her experiences tied together as I viewed them through multiple lenses, enabled her to better know herself. Julie will now approach her work with more self-awareness and may continue to reimagine it.

Another of my interviewees, Nancy, a mid-career librarian serving as Department Chair at her institution, also communicated that the interview process helped her reflect on her relationships among writing, refereeing, and reading.

So I guess one of the things I like now that I'm reflecting on this-one of the things I like about peer reviewing is that it keeps me reading things that maybe I wouldn't have otherwise read... So whether it's something job related or if it's for something that I'm writing it's sort of like "well I have to read this stuff because I need to work on this literature review for this thing that I'm working on," as opposed to like oh, in a perfect world where like every new issue would come in of all of the journals and I'd be like look at this, through the table of contents and sort of browsing, right. Like you have time for that. That's just not a thing. So peer reviewing helps me keep up with the literature because I'm reading the literature.

Just as several interviewees were able to reflect on their experiences in the "storying stories" process, so was I. Since completing 10 interviews and hearing 10 separate perspectives, I have been able to reflect on and reimagine my own practices. Hearing from many interviewees that they simply will not accept referee requests from non-OA journals, I felt empowered to do the same. Additionally, I was recently asked to review an article on open peer review; I inquired whether the journal would consider using an open peer-review process, especially given the article's subject. Based on this conversation, an open peer-review process for this article is currently underway.

Librarianship is a profession of praxis. We often have "best practices" or accepted ways of approaching our work. But how do we question them? Using stories, highly individualized and contextualized, to look at our own best practices may enable us to examine and explore unexpected results or consequences of widely accepted norms. What are the human experiences of best practices? Other possible avenues for investigation using nar- 
rative inquiry in our field may be investigations of promotion and tenure, experiences of librarians in community colleges, or those in "one-person shops." But this method may provide particularly robust information as we continue our concerted efforts to diversify our profession and allow for a more welcoming and inclusive professional environment for people from all socioeconomic, cultural, ethnic, racial, and gender experiences. Narrative inquiry allows us to listen to experiences; since these are individual and highly contextualized, we cannot "tokenize" them. After all, the purpose of narrative analysis is to contextualize individual experience rather than creating overarching themes. By listening to individual experiences of our colleagues, we may be able to reimagine accepted practices and approaches to our work.

\section{Conclusion}

Narrative inquiry is an impactful, albeit time-consuming, research method that has been rarely harnessed in LIS research. When done thoughtfully it will aid us in exploring how to better serve patrons, complement our existing research approaches, and allow us to reflexively examine our own community to foster lasting changes for LIS. So what does that mean for our librarianship praxis?

First, narrative inquiry, particularly the narrative analytic type, offers a complementary method for us to examine, understand, and react to the lived experiences of library patrons. What stories might a student tell about using library services or facilities? How is the library positioned within that narrative? Students may have stories about using the foot-washing station, the all-user bathroom, or even stories about using their information literacy skills in real life. ${ }^{40}$ Listening to contextualized lived experience offers us a view into reflecting on and potentially reimagining our approaches to services and facilities. Similarly, narrative analytic narrative inquiry can support the development of pedagogical practices in library and information literacy instruction and invite students into that process, empowering them to take part in their learning in new ways. ${ }^{41}$

Second, narrative inquiry offers us a powerful tool to examine and improve our own systems and processes. For example, we may ask to hear librarians' lived experiences of promotion and tenure reviews, experiences in our scholarly communication systems, or experiences with human resources practices intended to bolster diversity and equity. By asking for and listening to our colleagues' lived experiences, we invite the opportunity to reflect on and reimagine these systems. This work will be challenging. It will ask us to confront our understandings of deeply rooted cultural practices and question them.

Certainly these are not the only areas in which we can use narrative inquiry to inform our practice. LIS researchers interested in qualitative methods should consider whether narrative inquiry will support their work of asking big questions and placing them into context, rather than finding concrete, discernable answers. It is time that LIS research embrace the power of stories and lived experiences as part of our research paradigm.

Narrative inquiry work is time-consuming, nuanced, difficult, and emotional, but it is also deeply rewarding in its ability to surface the expanse of human experience and allow all players to reflect and reimagine future experience narratives. It affords us the opportunity to examine our humanistic librarianship work through a humanistic lens of curiosity and understanding; we can't know stories of human experience unless we ask for them, listen to them, and reflect on them. 


\section{Acknowledgments}

The author would like to acknowledge research participants for their participation and candor; Cass Kvenild and Sarah Ford for their comments on article drafts; the peer reviewers for their helpful comments; and Robert Schroeder for continually coaxing my curiosity about research methods. Financial support for this work was provided by a Portland State University Faculty Development Grant.

\section{Notes}

1. Coralie McCormack, "Storying Stories: A Narrative Approach to in-Depth Interview Conversations," International Journal of Social Research Methodology 7 (Apr. 2004): 219-36, https://doi.org/10.1080/13645570210166382.

2. McCormack, "Storying Stories."

3. Scott Walter, "Research and Writing," College \& Research Libraries 76, no. 5 (July 1, 2015): 564-65, https:// doi.org/10.5860/crl.76.5.564.

4. Emily Drabinski and Scott Walter, "Asking Questions That Matter," College \& Research Libraries 77, no. 3 (2016): 264-68, https://doi.org/10.5860/crl.77.3.264.

5. Robert Schroeder, "Evaluative Criteria for Autoethnographic Research: Who's to Judge?" in The Self as Subject: Autoethnographic Research into Identity, Culture, and Academic Librarianship, eds. Anne-Marie Dietering, Richard Stoddart, and Robert Schroeder (Chicago, IL: Association of College \& Research Libraries, 2017), 315-40.

6. Allison Benedetti, John Jackson, and Lili Luo, "Vignettes: Implications for LIS Research," College E Research Libraries 79, no. 2 (2018): 222-36, https://doi.org/10.1109/WPT.2015.7140128.

7. Andrew D. Asher and Lynda M. Duke, "Ethnography as an Assessment Tool: The ERIAL Project," in ARL Library Assessment Conference Building Effective Sustainable Practical Assessment, vol. October 26 (Library Assessment Conference, 2010), 461-68, available online at http://libraryassessment.org/bm doc/proceedings-lac-2010. pdf [accessed $<<$ need access date $>$ ].

8. Ahsan Ullah and Kanwal Ameen, "Account of Methodologies and Methods Applied in LIS Research: A Systematic Review," Library and Information Science Research 40, no. 1 (2018): 53-60, https://doi.org/10.1016/j. lisr.2018.03.002, 56.

9. Ullah and Ameen, "Account of Methodologies and Methods Applied in LIS Research," 57.

10. Hamid R. Jamali, “Does Research Using Qualitative Methods (Grounded Theory, Ethnography, and Phenomenology) Have More Impact?" Library and Information Science Research 40, no. 3/4 (2018): 203, https://doi. org/10.1016/j.lisr.2018.09.002.

11. Drabinski and Walter, "Asking Questions That Matter," 265.

12. Self as Subject: Autoethnographic Research into Identity, Culture, and Academic Librarianship, eds. Anne-Marie Dietering, Robert Schroeder, and Richard Stoddart (Chicago, IL: Association of College \& Research Libraries, 2017).

13. Dietering, Schroeder, and Stoddart, Self as Subject, 6.

14. Jeong-Hee Kim, Understanding Narrative Inquiry (Thousand Oaks, CA: SAGE Publications, 2016), 235.

15. D.E. Polkinghorne, "Narrative Configuration in Qualitative Analysis," Qualitative Studies in Education 8, no. 1 (1995): 5-23, 13.

16. Polkinghorne, "Narrative Configuration in Qualitative Analysis," 15.

17. Polkinghorne, "Narrative Configuration in Qualitative Analysis," 12.

18. McCormack, "Storying Stories."

19. Donna M. Lanclos, "Ethnographic Approaches to the Practices of Scholarly Communication: Tackling the Mess of Academia," Insights the UKSG Journal 29, no. 3 (Nov. 4, 2016): 240, https://doi.org/10.1629/uksg.316.

20. Bonnie Cheuk, "Applying Sense-Making and Narrative Techniques to Capture Lessons Learnt," Journal of Information \& Knowledge Management 6, no. 3 (2007): 165-71.

21. Cheuk, "Applying Sense-Making and Narrative Techniques to Capture Lessons Learnt," 165.

22. Rich Gazan, "Imposing Structures: Narrative Analysis and the Design of Information Systems," Library and Information Science Research 27, no. 3 (2005): 346-62, https://doi.org/10.1016/j.lisr.2005.04.004.

23. Stephanie A. Jones, "Illustrating the Narrative Process through Career Stories," School Libraries Worldwide 19, no. 2 (2013).

24. Marcia A. Mardis, “Transfer, Lead, Look Inward: Further Study of Preservice School Librarian's Development," Journal of Education for Library \& Information Science 54, no. 1 (2013): 37-54. 
25. Jones, "Illustrating the Narrative Process through Career Stories"; McCormack, "Storying Stories.

26. Frances Hultgren, "The Stranger's Tale: Information Seeking as an Outsider Activity," Journal of Documentation 69, no. 2 (Mar. 2013): 275-94, https://doi.org/10.1108/00220411311300075, 281.

27. Janet Ceja Alcalá et al., "Online Inclusive Pedagogy: A Call-and-Response Dialogue on Digital Storytelling," Education for Information 32, no. 1 (2016): 71-85, https://doi.org/10.3233/EFI-150963.

28. Kim L. Morrison, "Informed Asset-Based Pedagogy: Coming Correct, Counter-Stories from an Information Literacy Classroom," Library Trends 66, no. 2 (2019): 176-218, https://doi.org/10.1353/lib.2017.0034.

29. D. Clandinin, Handbook of Narrative Inquiry: Mapping a Methodology (Thousand Oaks, CA: SAGE Publications, Inc., 2007), https://doi.org/10.4135/9781452226552.

30. McCormack, "Storying Stories"; Coralie McCormack, "From Interview Transcript to Interpretive Story, Part 1: Viewing the Transcript through Multiple Lenses," Field Methods 12, no. 4 (2000): 282-97; Coralie McCormack, "From Interview Transcript to Interpretive Story, Part 2: Developing an Interpretive Story," Field Methods 12, no. 4 (2000): 298-315.

31. Debbie Pushor and D. Jean Clandinin, "The Interconnections between Narrative Inquiry and Action Research," in SAGE Handbook of Educational Action Research (Thousand Oaks, CA: SAGE Publications, Inc., 2012), 290-300, https://doi.org/10.4135/9780857021021.

32. Gail Crimmins, "The Intrinsic Pleasure of Being Present with/in Humanistic Research," in Producing Pleasure in the Contemporary University, eds. Stewart Riddle, Marcus K. Harmes, and Patrick Alan Danaher (Rotterdam, Netherlands: Sense Publishers, 2017), 95-105.

33. McCormack, "Storying Stories," 223.

34. Morrison, "Informed Asset-Based Pedagogy," 212.

35. Kim, Understanding Narrative Inquiry, 106.

36. Andrew C. Sparkes, "Embodiment, Academics, and the Audit Culture: A Story Seeking Consideration," Qualitative Research 7, no. 4 (2007): 521-50, https://doi.org/10.1177/1468794107082306.

37. Sparkes, "Embodiment, Academics, and the Audit Culture," 521.

38. Sparkes, "Embodiment, Academics, and the Audit Culture," 541.

39. Pushor and Clandinin, "The Interconnections between Narrative Inquiry and Action Research."

40. Hultgren, "The Stranger's Tale."

41. Alcalá et al., "Online Inclusive Pedagogy"; Morrison, "Informed Asset-Based Pedagogy." 